\title{
Experimental constraints on potassium isotope fractionation between potassium solutions and clay minerals
}

\author{
XINYANG CHEN ${ }^{1}$, BRIAN BEARD ${ }^{2}$, CLARK JOHNSON ${ }^{2}$ \\ AND XIN-YUAN ZHENG ${ }^{1}$ \\ ${ }^{1}$ University of Minnesota - Twin Cities \\ ${ }^{2}$ University of Wisconsin-Madison \\ Presenting Author: chen7315@umn.edu
}

Potassium $(\mathrm{K})$ is primarily hosted in silicates, in particular clays, stable $\mathrm{K}$ isotopes $\left({ }^{41} \mathrm{~K} /{ }^{39} \mathrm{~K}\right.$ or $\left.\delta^{41} \mathrm{~K}\right)$ are therefore promising tracers for silicate weathering. One of the novel discoveries resulting from recent advance in high-precision stable $\mathrm{K}$ isotope analysis is that the $\delta^{41} \mathrm{~K}$ value of seawater is $\sim 0.6 \%$ higher than that of the bulk silicate Earth. This difference has important bearing on the global $\mathrm{K}$ cycle and the intimately linked global carbon cycle, but its exact cause remains unknown. Formation of secondary clays during continental weathering is considered to increase $\delta^{41} \mathrm{~K}$ values of river waters, but existing data seem to suggest that the riverine input is unlikely to fully explain the $\sim 0.6 \%$ difference. Other processes such as authigenic clay formation and cation-exchange with clay minerals in the ocean are postulated to have played important roles. Testing these hypotheses and unambiguous interpretation of field $\delta^{41} \mathrm{~K}$ data require detailed knowledge on $\mathrm{K}$ isotope fractionation between solutions and clay minerals.

We conducted controlled experiments to constrain $\mathrm{K}$ isotope fractionation between aqueous $\mathrm{K}$ and representative clay minerals, including kaolinite, smectites (montmorillonite and nontronite), and illite. Three types of experimental techniques were used for each clay at circumneutral $\mathrm{pH}$ and room temperature. Products including solutions, $\mathrm{K}$ extracted from clays, and residues were analyzed. The first technique is the conventional exchange experiment where parallel reactors with identical quantities of $\mathrm{K}$ solution and clay were sampled at different reaction time over a period of $\sim 1$ month. The second technique involved repeated reaction of the same $\mathrm{KCl}$ solution with several batches of fresh clay, with each cycle removing $\sim 50 \% \mathrm{~K}$ from the solution. This method amplifies the effect of $\mathrm{K}$ isotope fractionation, so small fractionation could be more precisely constrained. In the third type of experiments, clay minerals, pre-equilibrated in $\mathrm{K}$ solution, were reacted with ${ }^{40} \mathrm{~K}$ enriched tracer solutions at near chemical equilibrium. This allows for quantification of $\mathrm{K}$ isotope exchange kinetics, and it also elucidates whether there is continued aqueous $\mathrm{K}$ exchange with non-expandable interlayers in illite at chemical equilibrium. We will highlight implications and significance of our results during this conference. 